\title{
Synthesis of $\mathrm{SnO}_{2}-\mathrm{ZnO}$ Core-Shell Nanowires and Their Optoelectronic Properties
}

Ko-Ying Pan, ${ }^{1}$ Yu-Hung Lin, ${ }^{1}$ Po-Sheng Lee, ${ }^{1}$ Jyh-Ming Wu, ${ }^{2}$ and Han C. Shih ${ }^{1,3}$

${ }^{1}$ Department of Materials Science and Engineering, National Tsing Hua University, Hsinchu 300, Taiwan

${ }^{2}$ Department of Materials Science and Engineering, Feng Chia University, Taichung 407, Taiwan

${ }^{3}$ Institute of Materials Science and Nanotechnology, Chinese Culture University, Taipei 111, Taiwan

Correspondence should be addressed to Han C. Shih, hcshih@mx.nthu.edu.tw

Received 25 August 2011; Revised 2 November 2011; Accepted 2 November 2011

Academic Editor: Istvan Robel

Copyright (C) 2012 Ko-Ying Pan et al. This is an open access article distributed under the Creative Commons Attribution License, which permits unrestricted use, distribution, and reproduction in any medium, provided the original work is properly cited.

\begin{abstract}
Zinc oxides deposited on Tin dioxide nanowires have been successfully synthesized by atomic layer deposition (ALD). The diameter of $\mathrm{SnO}_{2}-\mathrm{ZnO}$ core-shell nanowires is $100 \mathrm{~nm}$ by ALD 200 cycles. The result of electricity measurements shows that the resistance of $\mathrm{SnO}_{2}-\mathrm{ZnO}$ core-shell nanowires (ALD: 200 cycles) is $925 \Omega$, which is much lower than pure $\mathrm{SnO}_{2}$ nanowires $\left(3.6 \times 10^{6} \Omega\right.$ ). The result of UV light test shows that the recovery time of $\mathrm{SnO}_{2}-\mathrm{ZnO}$ core-shell nanowires (ALD: 200 cycles) is 328 seconds, which is lower than pure $\mathrm{SnO}_{2}$ nanowires (938 seconds). These results demonstrated that the $\mathrm{SnO}_{2}-\mathrm{ZnO}$ core-shell nanowires have potential application as UV photodetectors with high photon-sensing properties.
\end{abstract}

\section{Introduction}

Tin dioxide $\left(\mathrm{SnO}_{2}\right)$ and zinc oxide $(\mathrm{ZnO})$, world-renown ntype multifunctional semiconductors, have wide direct bandgap energy: 3.6 and $3.37 \mathrm{eV}$ at $300 \mathrm{~K}$, respectively. Furthermore, because of the very large length-to-diameter and surface-to-volume ratios in nanoscale regime, the gas sensing and optoelectronic properties of one-dimensional $\mathrm{SnO}_{2}$ and $\mathrm{ZnO}$ nanostructures are highly sensitive to adsorbed species on their own surface. Owing to special physical and chemical characteristics of one-dimensional $\mathrm{SnO}_{2}$ and $\mathrm{ZnO}$ nanowires, plenty of nanocompounds based on them have been widely applied to many industrial places, such as field emission devices [1], lithium-ion batteries [2], optoelectronic devices [3-6], and gas sensors [6-10]. However, upgrading the optoelectronic sensitivity is still a challenge for $\mathrm{SnO}_{2}$ nanostructure-based photodetectors.

In recent years, many literatures have demonstrated that nanocompounds of $\mathrm{SnO}_{2}$ and $\mathrm{ZnO}$ which belong to a heterocombination acted with good chemical and physical properties exceeding to their individual materials [11-13]. Most of all, a synthesis of core-shell nanostructure is a considered method for strongly improving sensing properties of $\mathrm{SnO}_{2}$ nanowires since surface states affects the sensing properties significantly.

In this study, $\mathrm{SnO}_{2}-\mathrm{ZnO}$ core-shell nanowires were synthesized by a step-by-step manufacture. First, $\mathrm{SnO}_{2}$ nanowires were fabricated by thermal evaporation. Second, $\mathrm{ZnO}$ layers were deposited on $\mathrm{SnO}_{2}$ nanowires by atomic layer deposition. Atomic layer deposition (ALD), a chemical vapor deposition, is a cutting-edge technique for the good controllable deposition of inorganic layers and has been commonly applied to semiconductor industries. In particular, the self-limiting gas-solid growth features of the ALD growth expedites the growth of thin films and nanomaterials with pretty accurate thickness and good uniformity.A few research of $\mathrm{SnO}_{2}-\mathrm{ZnO}$ core-shell nanowires focuses on enhancement of optoelectronic sensing, so their optoelectronic properties under UV light were investigated.

\section{Experimental}

There are two steps in this fabrication of $\mathrm{SnO}_{2}-\mathrm{ZnO}$ coreshell nanowires. In advance, an Au layer (about $30 \AA$ ), a catalyst in this fabrication, was coated on aluminum substrates by sputtering. In the first step, Tin oxide nanowires were 


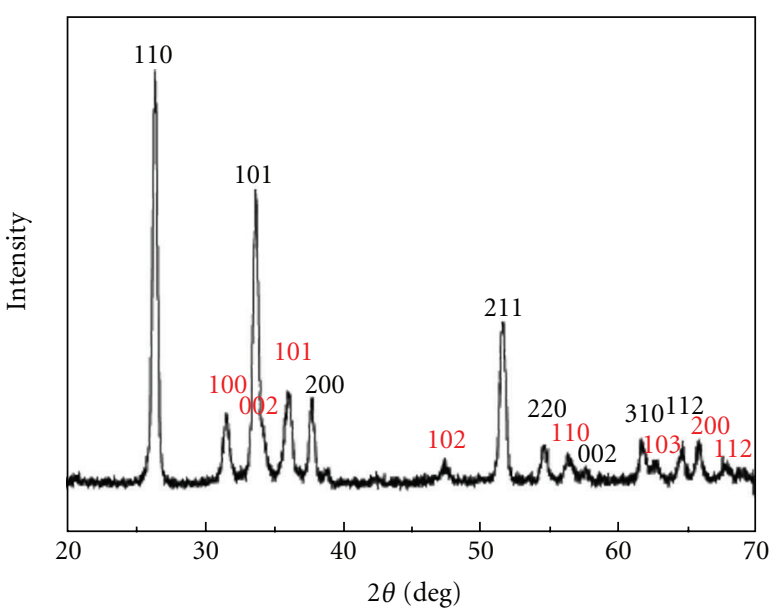

(a)

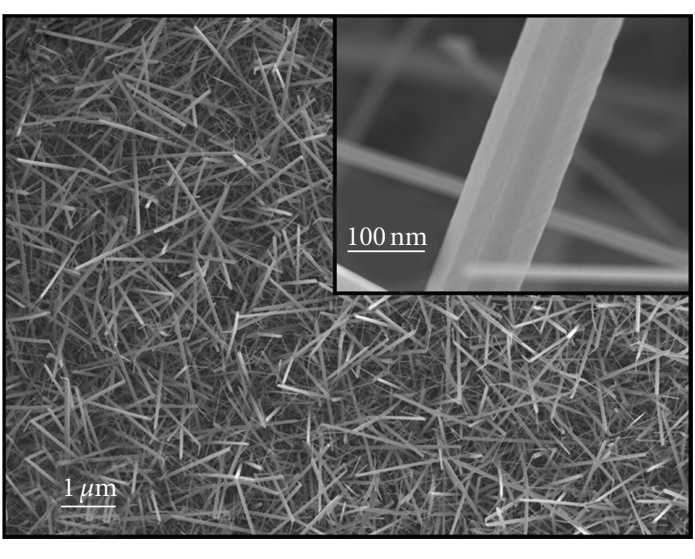

(b)

FIgURE 1: (a) XRD pattern (b) SEM image of $\mathrm{SnO}_{2}-\mathrm{ZnO}$ core-shell nanowires (ALD: 200 cycles).

fabricated on aluminum substrates by thermal evaporation. High quality $0.4 \mathrm{~g}$ Sn powders (Aldrich, purity $99.99 \%$ ) and several aluminum substrates were situated in an $\mathrm{Al}$ boat and then placed the $\mathrm{Al}$ boat in the heating area of a quartz tube. In the growth of Sn nanowires, the pressure inside the quartz tube was kept up at 1 Torr by a rotary pump. The working conditions of this process were as follows. (1) Raising the temperature to $950^{\circ} \mathrm{C}$ with $20^{\circ} \mathrm{C} / \mathrm{min}$ was at a constant flow rate of $10 \mathrm{sccm} \mathrm{Ar}$ gas. (2) Maintaining the temperature at $950^{\circ} \mathrm{C}$ for 1 hour was at a constant flow rate of mixed gas of $10 \mathrm{sccm} \mathrm{Ar}$ and $1 \mathrm{sccm} \mathrm{O}$. (3) Cooling to the room temperature was under a constant flow rate of $10 \mathrm{sccm}$ of $\mathrm{Ar}$ gas.

In the second step, a $\mathrm{ZnO}$ layer was coated on $\mathrm{SnO}_{2}$ nanowires by atomic layer deposition (ALD) [14-16]. The precursors were DEZ $\left(\mathrm{Zn}\left(\mathrm{C}_{2} \mathrm{H}_{5}\right)_{2}\right.$, Aldrich, purity $\left.98 \%\right)$ and $\mathrm{H}_{2} \mathrm{O}$ (purity $99.999 \%$ ) in $200 \mathrm{ALD}$ reaction cycles. Every single cycle, a $60 \mathrm{~ms}$ DEZ pulse and a $60 \mathrm{~ms} \mathrm{H}_{2} \mathrm{O}$ pulse were sequentially delivered into the ALD chamber by $5 \mathrm{~s}$ of purging with $\mathrm{N}_{2}$ (purity $99.9995 \%$ ). The pressure of chamber was maintained 1 Torr in the ALD reaction.

The morphology, crystal structure, and chemical composition of the $\mathrm{SnO}_{2}-\mathrm{ZnO}$ core-shell nanowires were analyzed by a field emission-scanning electron microscope (FESEM, JEOL JSM-6900F), a MAC glancing incident X-ray spectrometer with an incident angle of $0.5^{\circ}$, a high-resolution transmission electron microscope (HRTEM, JEOL, JEM2010), and X-ray photoelectron spectroscopy (XPS PerkinElmer Model PHI1600 system). In order to test the optoelectronic properties of $\mathrm{SnO}_{2}-\mathrm{ZnO}$ core-shell nanowires, the measurements of $\mathrm{I}-\mathrm{V}$ curves via a constant voltage $(5 \mathrm{~V})$ and photoresponse curves under UV light $(\lambda=365 \mathrm{~nm}$ and intensity is $17.1 \mathrm{~W} / \mathrm{m}^{2}$ ) were handled.

\section{Results and Discussion}

Figure 1(a) shows the XRD $\theta-2 \theta$ diffraction pattern of the $\mathrm{SnO}_{2}-\mathrm{ZnO}$ core-shell nanowires obtained after $200 \mathrm{ALD}$ reaction cycles. Red numbers (100), (002), and (101) are the main planes in $\mathrm{ZnO}$ with hexagonal wurtzite structure, and this XRD pattern corresponds with JCPDS: 89-1397. The lattice constants of hexagonal wurtzite structure are as follows: $a=b=3.253 \AA$ and $c=5.213 \AA$. Black numbers are the main planes in $\mathrm{SnO}_{2}$ with tetragonal rutile structure with lattice constants: $a=b=4.737 \AA, c=3.187 \AA$, and this XRD pattern matches up with JCPDS: $88-0287$. Figure $1(\mathrm{~b})$ is the SEM image of the $\mathrm{SnO}_{2}-\mathrm{ZnO}$ core-shell nanowires obtained after 200 ALD reaction cycles, and the enlarged image is in the upper right corner. According to these images, the abundant $\mathrm{SnO}_{2}-\mathrm{ZnO}$ core-shell nanowires with dimensions of $100-150 \mathrm{~nm}$ in diameters and several micrometers in length have been produced. These results demonstrate that the nanocompound is made of $\mathrm{SnO}_{2}$ and $\mathrm{ZnO}$ without other materials, signifying that the high quality nanocompounds of $\mathrm{SnO}_{2}-\mathrm{ZnO}$ have been successfully prepared.

To further investigate the detailed microstructure of $\mathrm{SnO}_{2}-\mathrm{ZnO}$ core-shell nanowires, taking images by TEM was performed. Figures 2(a) and 2(b) show a low-magnification TEM image. The diameter of core-shell nanowires is $100 \mathrm{~nm}$, and the thickness of $\mathrm{ZnO}$ shell layer is $25 \mathrm{~nm}$. From Figure 2(c), the HRTEM image of core-shell $\mathrm{SnO}_{2}-\mathrm{ZnO}$ nanowires shows that the lattice spacing between (0002) is $0.28 \mathrm{~nm}$, and the structure of $\mathrm{ZnO}$ that has hexagonal structure is corresponding. From Figure 2(d), the growth direction is [101], the lattice space is $0.26 \mathrm{~nm}$, and the angle between [101] and [ -101$]$ is 67.85 , which are consistent with the $\mathrm{SnO}_{2}$ that has tetragonal rutile structure. According to these TEM images, no doubt the core-shell nanostructure is certainly formed via two-step method.

In order to identify the chemical composition of the $\mathrm{SnO}_{2}-\mathrm{ZnO}$ core-shell nanowires and check the quality of $\mathrm{ZnO}$ deposited on $\mathrm{SnO}_{2}$ by ALD, the core-shell $\mathrm{SnO}_{2}-$ $\mathrm{ZnO}$ nanowires were additionally characterized by XPS. Figure $3(\mathrm{a})$ shows that the binding energy of $\mathrm{Zn}\left(2 \mathrm{p}_{3 / 2}\right)$ and $\mathrm{Zn}\left(2 \mathrm{p}_{1 / 2}\right)$ are $1021.9 \mathrm{eV}$ and $1044.9 \mathrm{eV}$, respectively. Figure 3(b) shows that the binding energy of $O(1 \mathrm{~s})$ is 


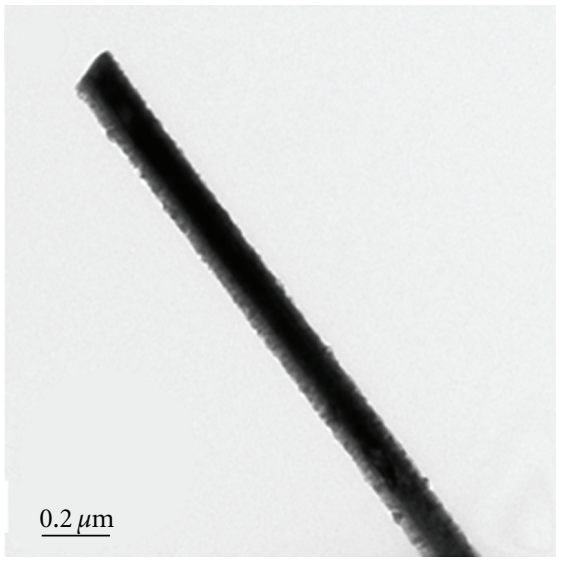

(a)

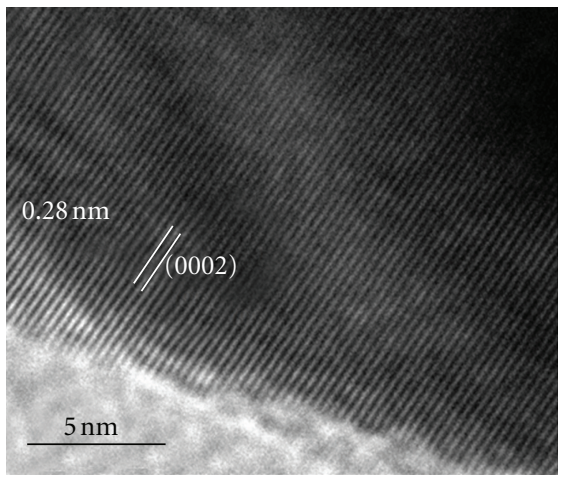

(c)

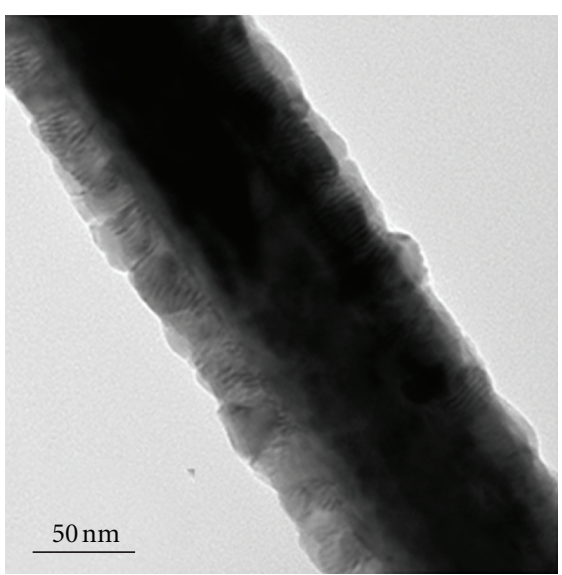

(b)

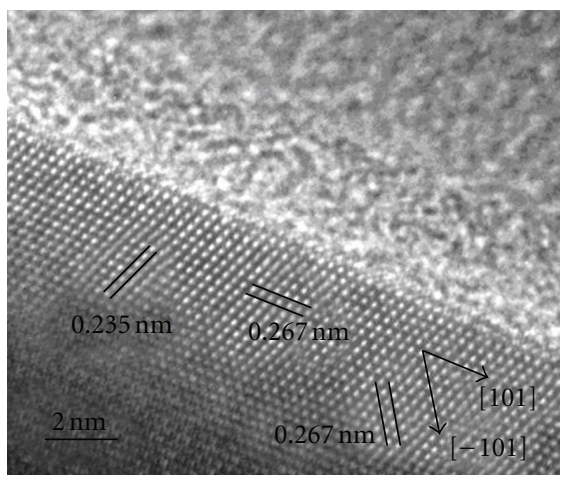

(d)

Figure 2: (a) and (b) Low-magnification TEM, (c) HRTEM image of a $\mathrm{SnO}_{2}-\mathrm{ZnO}$ core-shell nanowires (ALD: 200 cycles), and (d) HRTEM image of a $\mathrm{SnO}_{2}$ single nanowires.

$530.9 \mathrm{eV}$. Figure 3(c) shows that binding energy of $\mathrm{Sn}\left(3 \mathrm{~d}_{3 / 2}\right)$ and $\mathrm{Sn}\left(3 \mathrm{~d}_{5 / 2}\right)$ is $495.1 \mathrm{eV}$ and $487.5 \mathrm{eV}$. After integration of the area of three main elements "peaks by computer program", the atomic percentages of oxygen, zinc, and tin are 55.27, 41.7, and 3.03, respectively. Judging from XPS analysis, because the atomic percentage of $\mathrm{ZnO}$ is large in this compound, $\mathrm{ZnO}$ crystalline shell is definitely deposited on $\mathrm{SnO}_{2}$ nanowires by ALD.

By above material analyses, the confirmation of $\mathrm{SnO}_{2}-$ $\mathrm{ZnO}$ core-shell nanowires synthesized sequentially via thermal evaporation, and ALD was done. To determine the potential applicability of $\mathrm{SnO}_{2}-\mathrm{ZnO}$ core-shell nanowires in this study to photodetectors, their I-V curves and UV photon-sensing properties were investigated. Figure 4 shows the current-voltage (I-V) curves of $\mathrm{SnO}_{2}-\mathrm{ZnO}$ core-shell nanowires with ALD 200 cycles reaction (red line) and pure $\mathrm{SnO}_{2}$ nanowires (black line) at room temperature and atmospheric pressure. Two curves show a good ohmic contact between the nanocompounds and Ag electrodes. The electrical resistivity can be expressed as $R=\rho \times \mathrm{L} / \mathrm{A}$, and the electrical resistivity of $\mathrm{SnO}_{2}-\mathrm{ZnO}$ nanowires and pure $\mathrm{SnO}_{2}$ nanowires can be solved as $925 \Omega$ and $3.6 \times$ $10^{6} \Omega$, respectively. The electrical resistivity of core-shell nanostructure is much lower than pure nanowires. Because of that $\mathrm{ZnO}$ film of core-shell $\mathrm{SnO}_{2}-\mathrm{ZnO}$ nanowires is more compact than $\mathrm{SnO}_{2}$ nanowires, this effect is able to increase the film conductivity.

When setting up an electric circuit with core-shell nanostructures, there will be a strain in a heterointerface to keep from a deformation happened and decrease the total energy. Moreover, the band gap of core-shell materials will be reduced, and then the conductivity will be raised [17].

To investigate the application of $\mathrm{SnO}_{2}-\mathrm{ZnO}$ core-shell nanostructure and pure $\mathrm{SnO}_{2}$ nanowires for UV detectors, the optoelectronic response and recovery of the as-fabricated photodetectors were tested under emitted UV lamps $(\lambda=$ $365 \mathrm{~nm}$ ). The optoelectronic test unveils that the current very quickly rises to a steady level under UV light (UV light is on) and then increasingly recovers to the initial state in the dark (UV light is off). Figures 5(a) and 5(b) show the period photoresponse curve of pure $\mathrm{SnO}_{2}$ nanowires and $\mathrm{SnO}_{2}-\mathrm{ZnO}$ core-shell nanowires (200 ALD cycles), respectively. In previous studies [18], the opinion of these photoresponse curves was discussed. When the UV light is off, the species of oxygen molecular structure are chemoadsorbed on the interfaces of nanostructures because oxygen molecules catch free electrons, that is, $\mathrm{O}_{2(\mathrm{~g})}+\mathrm{e}^{-} \rightarrow \mathrm{O}_{2(\mathrm{ad})}{ }^{-}$. Therefore, a low conductivity depletion layer is formed near the surface of nanowires, and the nonmaterial's conductivity will be decreased. When UV light is on, electron-hole 


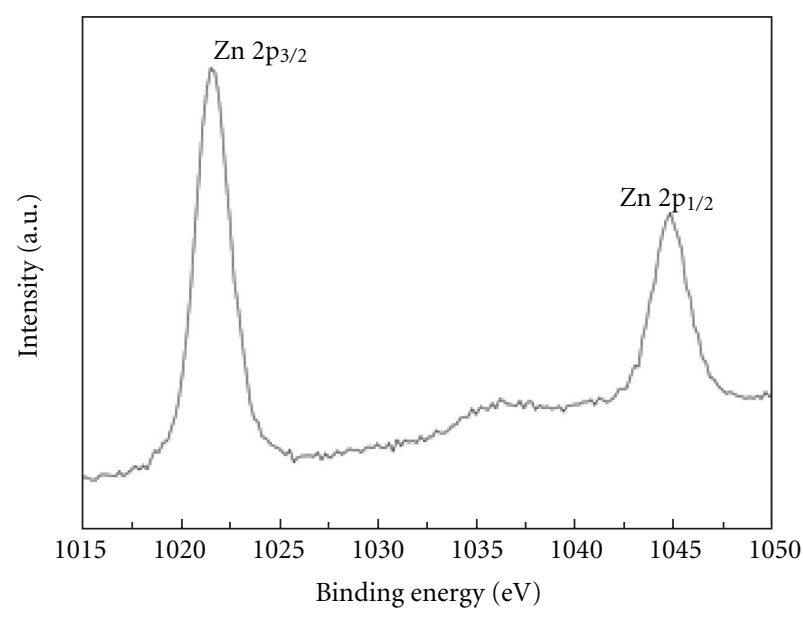

(a)

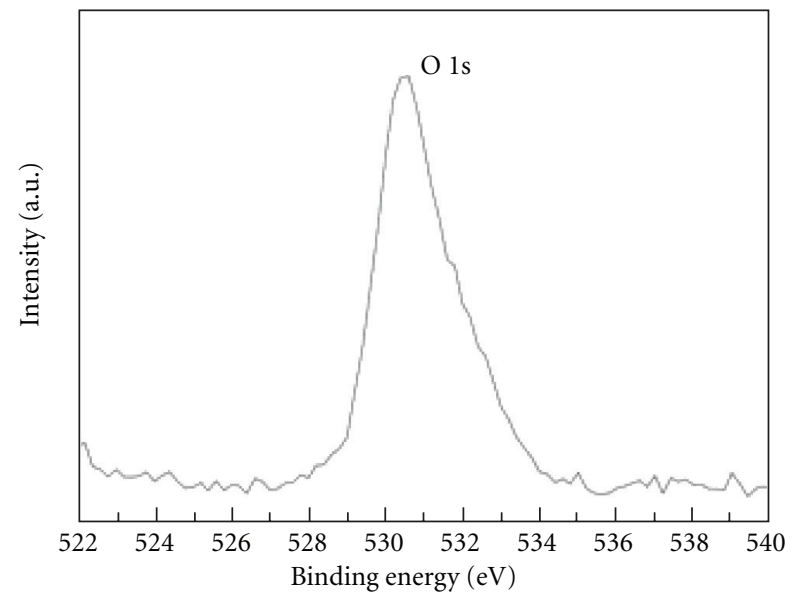

(b)

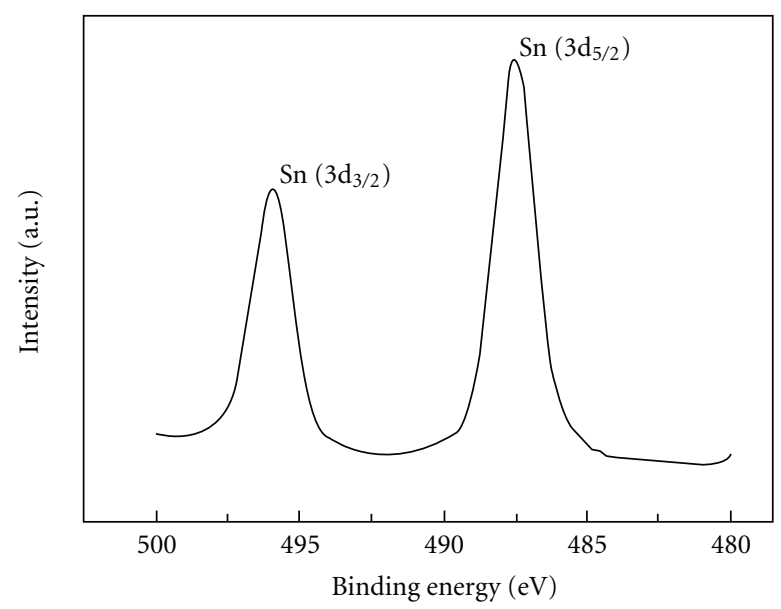

(c)

FIgure 3: The XPS (a) Zn 2p (b) O 1S (c) Sn 3d spectrum.

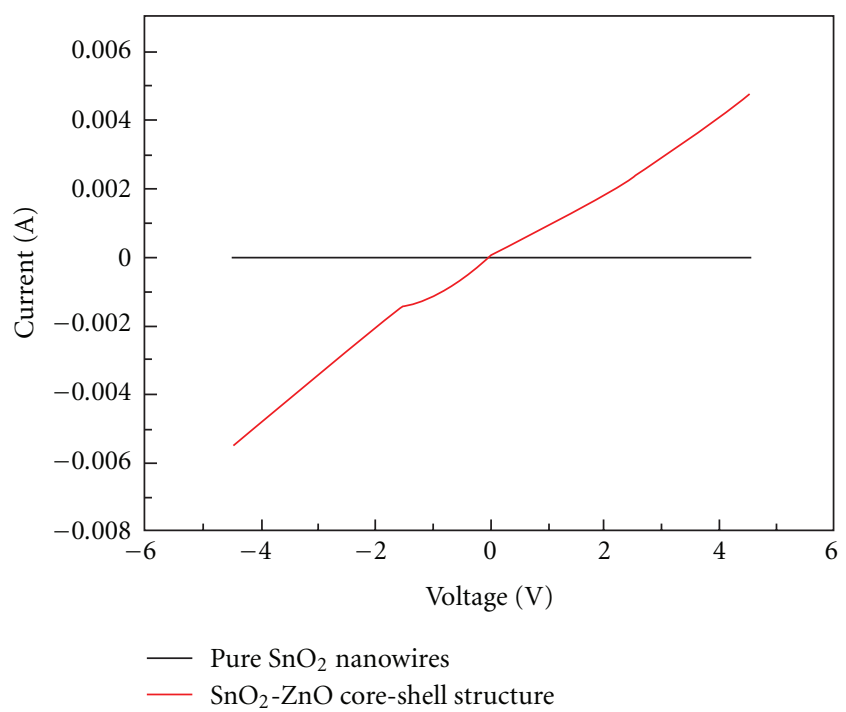

Figure 4: The I-V curve of $\mathrm{SnO}_{2}-\mathrm{ZnO}$ core-shell nanowires (ALD: 200 cycles) and pure $\mathrm{SnO}_{2}$ nanowires. pairs follow this reaction, $\mathrm{h} v \rightarrow \mathrm{e}^{-}+\mathrm{h}^{+}$, and will be happened in the nanowires. The photoinduced holes will relocate to the surface and recombine with the oxygen ions, that is, $\mathrm{h}^{+}+\mathrm{O}_{2(\mathrm{ad})}{ }^{-} \rightarrow \mathrm{O}_{2(\mathrm{~g})}$. At the same time, the photon-generated electronics are able to play free electrons and upgrade the electron conductance of nanowires. The photocurrent rapidly increases with the reduced depletion layer.

Figure 5(a) shows that since UV light is on, the current is $3.47 \times 10^{-6} \mathrm{~A}$. After 50 seconds, the current increases to 7.23 $\times 10^{-6} \mathrm{~A}$. The slope is 0.0752 . From Figure $5(\mathrm{~b})$, since UV light is on, the current is $3.53 \times 10^{-5} \mathrm{~A}$. After 50 seconds, the current lifts to $5.35 \times 10^{-5} \mathrm{~A}$. The slope is 0.0364 . Therefore, the device based on pure $\mathrm{SnO}_{2}$ nanowires has a better sensitivity than based on $\mathrm{SnO}_{2}-\mathrm{ZnO}$ core-shell nanowires. In terms of photosensitivity, the pure $\mathrm{SnO}_{2}$ nanowires are little larger than the $\mathrm{SnO}_{2}-\mathrm{ZnO}$ core-shell nanowires, and two depletion areas of core-shell nanostructure might be the cause for this phenomenon. However, the recovery time of core-shell $\mathrm{SnO}_{2}-\mathrm{ZnO}$ nanowires is just 328 seconds, which is much shorter than that of pure $\mathrm{SnO}_{2}$ nanowires 


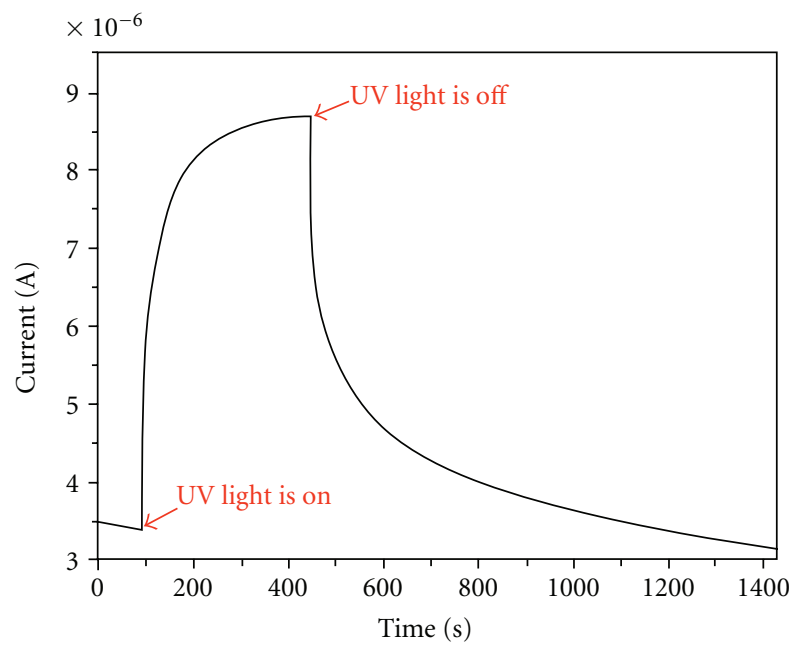

(a)

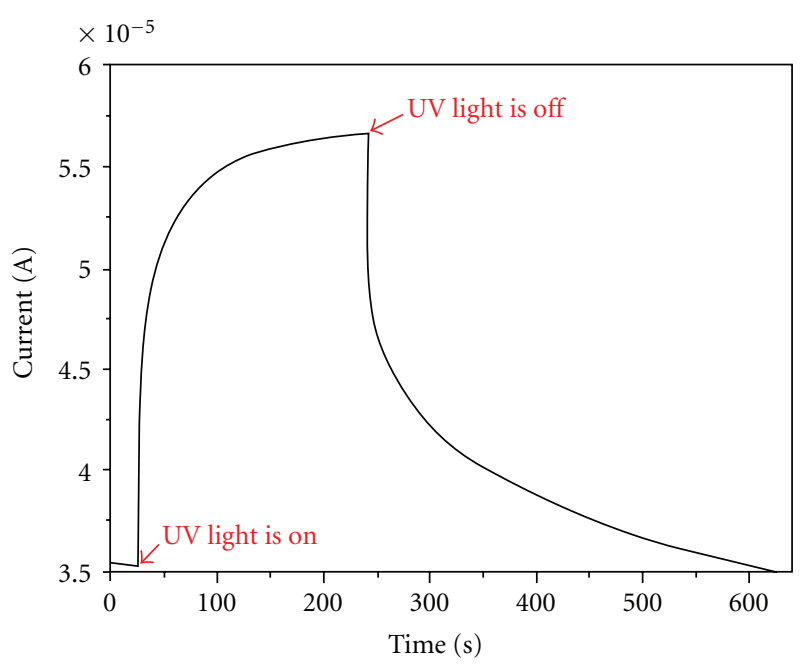

(b)

FIgURE 5: Photoresponse curves of (a) pure $\mathrm{SnO}_{2}$ nanowires and (b) $\mathrm{SnO}_{2}-\mathrm{ZnO}$ core-shell nanowires-based photodetectors.

(938 seconds). It is a reason that a superposition of the homo- and heterointerfaces formed at the junctions may be the root cause for the decreased recovery time compared with the detector judging from the nanowires without the shell layer $[19,20]$. All in all, the $\mathrm{SnO}_{2}-\mathrm{ZnO}$ core-shell nanowires have positive characteristics and applications in the manufacture of photodetectors.

\section{Conclusion}

$\mathrm{SnO}_{2}-\mathrm{ZnO}$ core-shell nanowires have been successfully fabricated by a step-by-step process. First, $\mathrm{SnO}_{2}$ nanowires were synthesized by thermal evaporation. Sequentially, $\mathrm{ZnO}$ shell layers were deposited by ALD. The $\mathrm{SnO}_{2}-\mathrm{ZnO}$ coreshell nanowire-based photodetectors has the low electrical resistance ( $925 \Omega$ ) and the short recovery time (328 seconds), compared with pure $\mathrm{SnO}_{2}$ nanowires. Thanks to excellent optoelectron abilities, the $\mathrm{SnO}_{2}-\mathrm{ZnO}$ core-shell nanowires are the promising candidates as photodetectors.

\section{References}

[1] Q. Wan, E. N. Dattoli, and W. Lu, "Transparent metallic Sbdoped $\mathrm{SnO}_{2}$ nanowires," Applied Physics Letters, vol. 90, no. 22, Article ID 222107, 2007.

[2] S. L. Chou, J. Z. Wang, C. Zhong, M. M. Rahman, H. K. Liu, and S. X. Dou, "A facile route to carbon-coated $\mathrm{SnO}_{2}$ nanoparticles combined with a new binder for enhanced cyclability of Li-ion rechargeable batteries," Electrochimica Acta, vol. 54, no. 28, pp. 7519-7524, 2009.

[3] P. S. Lee, Y. H. Lin, Y. S. Chang, J. M. Wu, and H. C. Shih, "Growth and characterization of thermally evaporated ATO nanowires," Thin Solid Films, vol. 519, no. 5, pp. 1749-1754, 2010.

[4] Y. H. Lin, Y. C. Hsueh, C. C. Wang, J. M. Wu, T. P. Perng, and H. C. Shih, "Enhancing the photon-sensing properties of $\mathrm{ZnO}$ nanowires by atomic layer deposition of platinum,"
Electrochemical and Solid-State Letters, vol. 13, no. 12, pp. K93-K95, 2010.

[5] Q. Kuang, Z. Y. Jiang, Z. X. Xie et al., "Tailoring the optical property by a three-dimensional epitaxial heterostructure: a case of $\mathrm{ZnO} / \mathrm{SnO}_{2}$," Journal of the American Chemical Society, vol. 127, no. 33, pp. 11777-11784, 2005.

[6] Y. H. Lin, Y. C. Hsueh, P. S. Lee et al., "Preparation of $\mathrm{Pt} / \mathrm{SnO}_{2}$ core-shell nanowires with enhanced ethanol gas- and photonsensing properties," Journal of the Electrochemical Society, vol. 157, no. 9, pp. K206-K210, 2010.

[7] A. Kolmakov, Y. Zhang, G. Cheng, and M. Moskovits, "Detection of $\mathrm{CO}$ and $\mathrm{O}_{2}$ using tin oxide nanowire sensors," Advanced Materials, vol. 15, no. 12, pp. 997-1000, 2003.

[8] V. Kumar, S. Sen, K. P. Muthe, N. K. Gaur, S. K. Gupta, and J. V. Yakhmi, "Copper doped $\mathrm{SnO}_{2}$ nanowires as highly sensitive $\mathrm{H}_{2} \mathrm{~S}$ gas sensor," Sensors and Actuators B, vol. 138, no. 2, pp. 587-590, 2009.

[9] D. Wang, X. Chu, and M. Gong, "Gas-sensing properties of sensors based on single-crystalline $\mathrm{SnO}_{2}$ nanorods prepared by a simple molten-salt method," Sensors and Actuators B, vol. 117, no. 1, pp. 183-187, 2006.

[10] X. Wang, J. Zhang, and Z. Zhu, "Ammonia sensing characteristics of $\mathrm{ZnO}$ nanowires studied by quartz crystal microbalance," Applied Surface Science, vol. 252, no. 6, pp. 2404-2411, 2006.

[11] I. S. Hwang, S. J. Kim, J. K. Choi et al., "Synthesis and gas sensing characteristics of highly crystalline $\mathrm{ZnO}-\mathrm{SnO}_{2}$ coreshell nanowires," Sensors and Actuators B, vol. 148, no. 2, pp. 595-600, 2010.

[12] M. Shahid, I. Shakir, S. J. Yang, and D. J. Kang, "Facile synthesis of core-shell $\mathrm{SnO}_{2} / \mathrm{V}_{2} \mathrm{O}_{5}$ nanowires and their efficient photocatalytic property," Materials Chemistry and Physics, vol. 124, no. 1, pp. 619-622, 2010.

[13] Y. T. Yu and P. Dutta, "Examination of $\mathrm{Au} / \mathrm{SnO}_{2}$ core-shell architecture nanoparticle for low temperature gas sensing applications," Sensors and Actuators B, vol. 157, no. 2, pp. 444449, 2011.

[14] R. L. Puurunen, "Surface chemistry of atomic layer deposition: a case study for the trimethylaluminum/water process," Journal of Applied Physics, vol. 97, no. 12, Article ID 121301, pp. 1-52, 2005. 
[15] L. Niinistö, M. Ritala, and M. Leskelä, "Synthesis of oxide thin films and overlayers by atomic layer epitaxy for advanced applications," Materials Science and Engineering B, vol. 41, no. 1, pp. 23-29, 1996.

[16] M. Leskelä and M. Ritala, "Atomic layer deposition (ALD): from precursors to thin film structures," Thin Solid Films, vol. 409, no. 1, pp. 138-146, 2002.

[17] J. Schrier, D. O. Demchenko, L. W. Wang, and A. P. Alivisatos, "Optical properties of $\mathrm{ZnO} / \mathrm{ZnS}$ and $\mathrm{ZnO} / \mathrm{ZnTe}$ heterostructures for photovoltaic applications," Nano Letters, vol. 7, no. 8, pp. 2377-2382, 2007.

[18] Y. H. Lin, C. C. Kuo, J. M. Wu, U. S. Chen, Y. S. Chang, and H. C. Shih, "Characterization and cathodoluminescence of beaklike $\mathrm{SnO}_{2}$ nanorods," Japanese Journal of Applied Physics, vol. 47, no. 10, pp. 8141-8144, 2008.

[19] S. W. Choi, J. Y. Park, and S. S. Kim, "Synthesis of $\mathrm{SnO}_{2}-\mathrm{ZnO}$ core-shell nanofibers via a novel two-step process and their gas sensing properties," Nanotechnology, vol. 20, no. 46, Article ID 465603, 2009.

[20] J. M. Wu and C. H. Kuo, "Ultraviolet photodetectors made from $\mathrm{SnO}_{2}$ nanowires," Thin Solid Films, vol. 517, no. 14, pp. 3870-3873, 2009. 

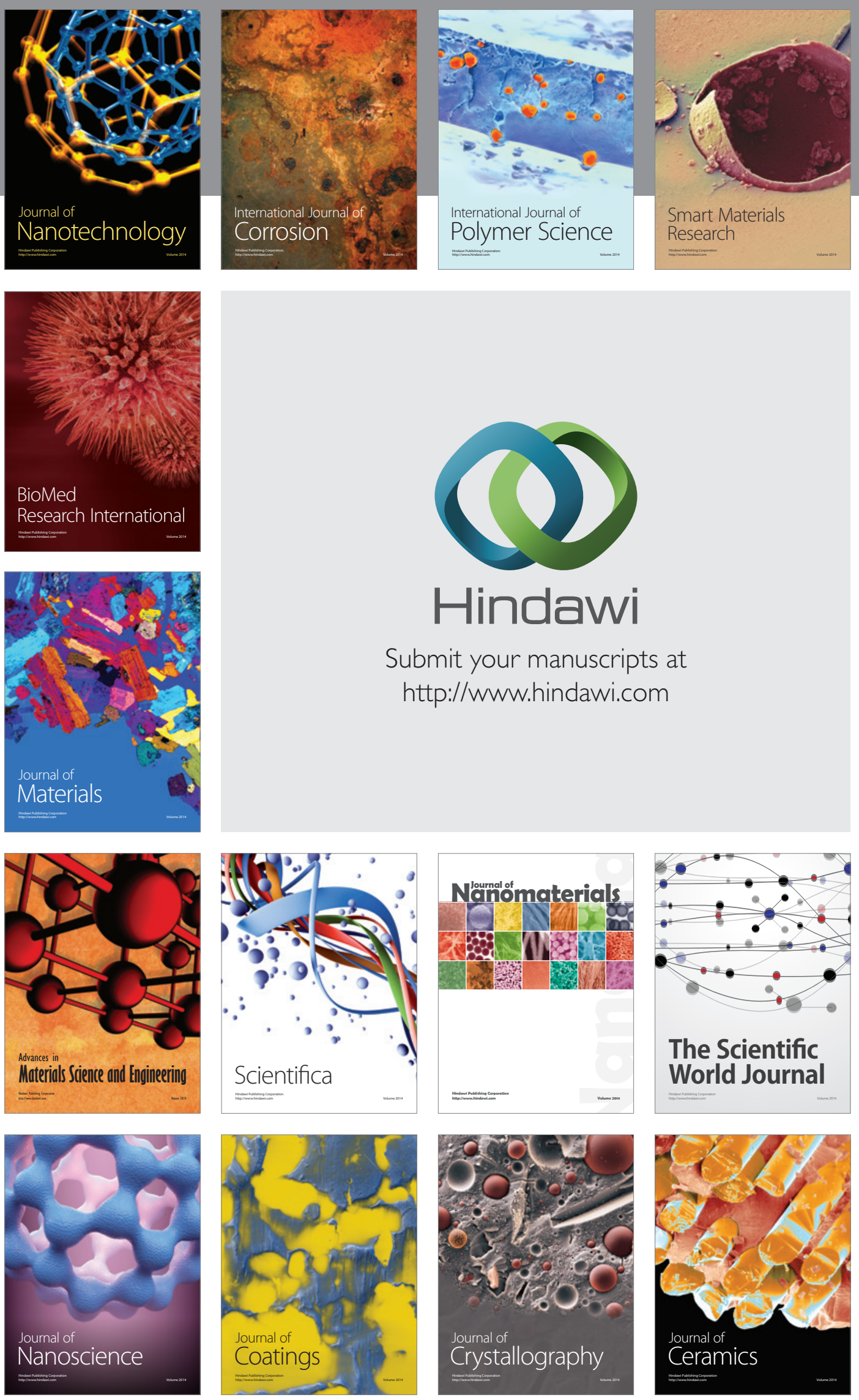

The Scientific World Journal

Submit your manuscripts at

http://www.hindawi.com

\section{World Journal}

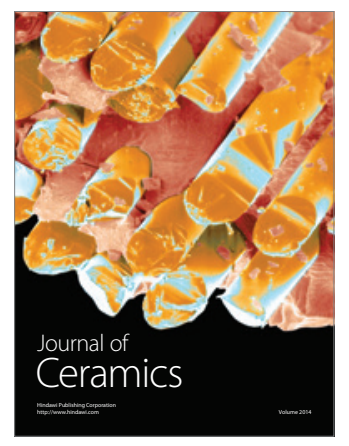

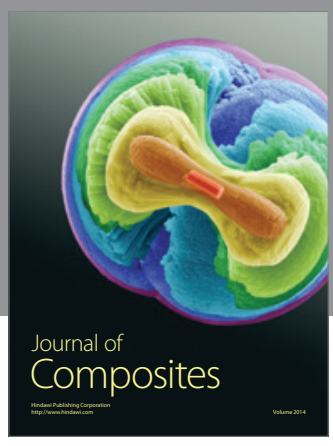
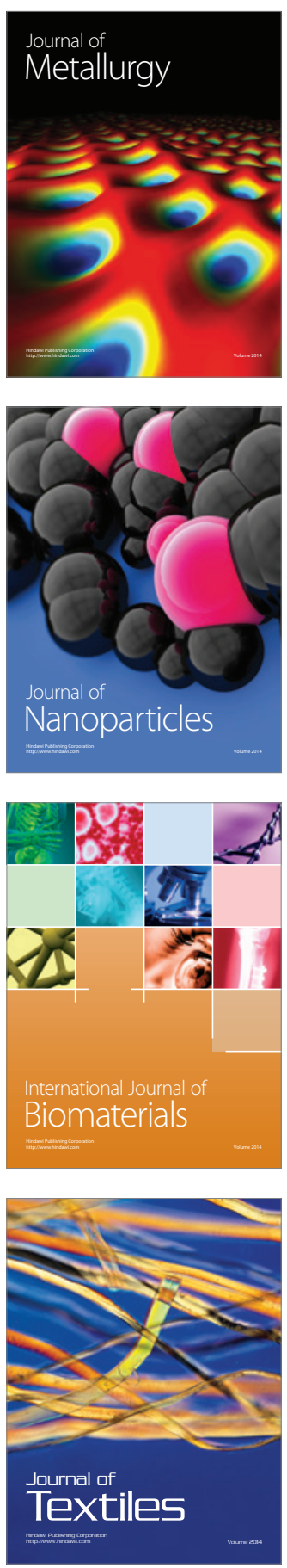